This is an open access article under the CC BY-NC-ND license (https://creativecommons.org/licenses/by-nc-nd/3.0/) Issue II, November 2019

ISBN 978-601-323-144-0

https://doi.org/10.31643/2019.018

\author{
Alimkul Aizhan \\ Master degree student, Abai KazNPU in Almaty, Kazakhstan \\ E-mail: alymkul_a@list.ru \\ ORCID ID: 0000-0002-8602-9781
}

\title{
Quality assessment system of secondary education in the Republic of Kazakhstan
}

\begin{abstract}
The background of this paper is to present the quality assessment system of secondary education in Kazakhstan. The principles of a new knowledge paradigm are reflected in the state program of education development for 2011-2020. During the course of its implementation, the issues of assessing quality for education, its measurement, improvement and control were updated. Over the years of our independence, Kazakhstan has emerged a holistic multilevel national system for quality assurance in education. The article presents the charactericts of the current Kazakhstan system of education quality assessment, including independ evaluation of quality, considered the contribution of NEQUS in school. In order to guarantee quality education Kazakhstan has established the National Education Quality Assessment System (NEQAS), to ensure the comparability of national and international indicators, as well as regional NEQAS structures for regional quality appraisal.
\end{abstract}

Keywords: system of quality assessment, secondary education, National Education Quality Assessment System, Unified National Testing.

\section{Introduction}

The development of the education system is a priority for Kazakhstan, as investment in education is key to the well-being of society as a whole. Education, which constitutes a major investment into human capital, is also a key driver of economic growth. In an integrated dynamic global market place, education systems must continually improve and work to adapt to changing circumstances. The State Programme of Education Development in the Republic of Kazakhstan for 2011- 2020 (SPED) is the foundation document driving education reform in the country. Although the SPED states that "in 2015, the transition period would be completed, and the education system of the Republic of Kazakhstan would correspond to the models of developed countries in its structure, content, management and financing mechanisms", no clear vision has been established for the second stage of this development for 2015 to 2020. This diagnostic report provides an analysis of the problems that the Kazakhstan system of education needs to address in the next stage of its development and is offered as a step towards this goal [1]. These reforms often include the adoption of laws and decrees that set specific rules and regulations for the promotion of quality in education.

The education system in Kazakhstan, which is based on the principle of continuity and consistency of curricula, comprises the following education levels:

$\checkmark$ Primary education is carried out in primary school (grades 1-5);

$\checkmark$ Basic secondary education is carried out in lower secondary school (grades 6-10);

$\checkmark$ General secondary education is carried out in upper secondary school (grades 11-12).

\section{Secondary education}

In secondary education, in spite of many initiatives and a strong will to reform, the current plans are poorly co-ordinated, insufficiently ambitious and lack an understanding of the educational principles and practices that need to be applied if Kazakhstan is to move forward nationally and onto the international stage in the way in which it seeks. Curriculum, assessment, textbooks, pedagogy, teacher training and school leadership all have to be developed together in a co-ordinated way with careful synchronisation. These aspects need to be informed by the same goals and values or they will undermine each other. National standards, subject programmes, pedagogy and textbooks need to be revised with a view to setting expectations for the development of more challenging intellectual function - comparing, analysing, applying, 
critiquing, inquiring, explaining, arguing - not just memorising and recalling. Unified National Testing (UNT), being one of the most powerful and dysfunctional elements of the education system in Kazakhstan, needs to be revised radically to ensure that it is testing the variety of intellectual tasks that the country (and the higher education system) should require of students. It should employ a wider range of contemporary assessment methods and provide a broader profile of students' achievement across a range of subjects and accomplishments. In the education sphere, there is a lack of agreement on what is meant by "trilingualism" and trilingual education; and, little is known of the results that have been achieved by students in various types of trilingual education programmes elsewhere in the world and how this was accomplished. Current planning is underway with insufficient knowledge about trilingual education, and based partly on some false assumptions. The levels of fluency to be achieved in Kazakh, Russian and English are insufficiently and inconsistently defined. Furthermore, curriculum goals are not fully aligned with the trilingual goals, and assessment of language learning is not aligned with curriculum intentions. These factors make it difficult to plan, among others, for curriculum and textbook development, and for teacher pre- and in-service training. Stakeholders in trilingual education are not co-operating sufficiently to achieve current government targets [2].

\section{Teachers and Teacher Education}

The teacher salary structure in the "stavka" system is fragmented, complex and difficult to administer. Teacher salaries need to be increased to place them above the national average rather than below in order to attract quality candidates. System efficiency indicators such as the student to teacher ratio are very low (average ratio 8.2). This requires careful analysis, and possibly, revision of school staffing norms and school network rationalisation. With regard to teacher education, there are serious issues related to attracting, recruiting, selecting and preparing high quality candidates to teach in Kazakhstan. Teacher education needs to be reformed urgently and systems along the teacher's career path need to be aligned in order to improve teachers' professional learning and development. Clear standards are needed that correlate to the vision of the teacher, the school and professional learning - and the application of these standards to the development of the teacher's education curriculum and to student/teacher assessment [3].

\section{Infrastructure and Resources}

Infrastructure is a major issue as many school buildings are unfit for purpose - as judged even against current standards of health and hygiene as well as educational functionality. Many existing schools lack the facilities and resources to provide a proper learning environment for e.g. the kind of practicals that are required or should be required if students are to learn to apply knowledge and learn to investigate natural phenomoenon for themselves; for work in the arts or for physical education. The Nazarbayev Intellectual Schools (NIS) schools are setting new national standards that are far out of reach of ordinary schools, although the NIS curriculum is still expected to be integrated into the mainstream [4].

\section{(NSQAE)}

One of the major achievements of the education system of the Republic of Kazakhstan in the years of independence was to create an effective national system of quality assessment in education (NSQAE) of the Republic of Kazakhstan.

The major tasks were the implementation of (NSQAE) National Assessment of Educational Achievements of Students at all levels of education, conduct systematic and comparative analysis of the quality of educational services to educational organizations, obtaining objective information about the state of the education system needed to ensure the constitutional rights of citizens to quality education and information society, comparative monitoring educational achievements of students in Kazakhstan with the educational achievements of students from other countries in international studies.

An Annual Message of the President of the Republic of Kazakhstan Nursultan Nazarbayev to people of Kazakhstan and the task set concerning the implementation of the independent national assessment of students' educational achievements in order to identify further ways of the education system development [5].

\section{Assessment: the Unified National Test (UNT)}

The UNT is, in our view, one of the most powerful as well as one of the most dysfunctional elements of the educational system in Kazakhstan. It is powerful because it plays a key role in determining students' future notably their access to higher education; teachers' and schools' performances are assessed by reference to their students' performance on UNT scores; and parents, teachers and students are all almost single-mindedly focused on their results. The UNT is dysfunctional from several points of view. More detailed analysis is needed than we have gone into here. Firstly, almost all of the UNT tests are based on the recall of various factual information. This is of course consistent with the way the national standards are expressed (see comments above), and it reinforces expectations of low-level intellectual competence. A few 
examples of UNT test questions set alongside questions from international examinations will perhaps serve to illustrate the low level of intellectual demands that characterizes the UNT [1].

Unified National Test has become the first and most important element NSEQA. Government Regulation of the Republic of Kazakhstan "On Introduction of Unified National Test" from March, 132004 a system of Unified National Test was introduced. Unified National Test (UNT) foresees the combination of final state certification of secondary school and entrance examinations applicants entering the secondary and higher educational institutions.

A prerequisite for the introduction of Unified National Test was the deficiency of objective, national procedures of education quality assessment at the final assessment of students and to the steady deterioration in the quality of secondary education in RK, as it was evidenced by the results of annual comprehensive testing of applicants.

The analysis of the situation in secondary education showed that factors preventing the provision of the quality of education is:

- subjectivity in assessing the academic achievement;

- lack of objective, external procedures of the assessment quality education at final certification of students;

- lack of motivation among students and teachers in the good results of the learning process;

- imperfection of the state compulsory standards of education;

- poor material-technical base of educational institutions;

- an inefficient mechanism for training, retraining and certification of teachers.

The socio-political prerequisites of UNT stemmed from the fact that in educational system there was no intellectual competition in determining the access to the next level of education (in particular for admission to higher education on a commercial basis), which has a negative effect on the overall level of intellectual development of young citizens of Kazakhstan. For instance, students had no motivation to compete for possession of more knowledge, as far as they had an access to higher education on a commercial basis, even with the lowest preparation. This situation was undermining the foundations of the intellectual security of the state and could lead to a complete devaluation of higher education. A similar situation exists in the final assessment for high school course.

With the introduction of UNT the practice of the most effective educational systems in countries such as the USA, UK, the Netherlands, Japan and others using Unified National Examinations in the form of testing to evaluate academic achievement was taken into account.

The goal of UNT consisted in creation of an independent national assessment of educational achievements, providing high quality of secondary education.

United National Test solves the following tasks:

- ensuring state control and education quality management through unified measuring materials;

- improving the objectivity, reliability, quality assessment;

- creating mechanisms for public control over the quality of education through the transparency of the results of UNT;

- ensuring equity in access to higher and secondary vocational education.

The introduction in 2004 of Unified National Test and intermediate certification of university students ensured the creation of a full system of independent national control of knowledge. Within the framework of nationwide control systems of knowledge in the country there was made a comprehensive testing and use of information and telecommunication technology. The existing technology of the integrated test for admission to higher institutions has predetermined the basic principles of UNT.

The following distribution functions were effected between UNT parties. Ministry of Education and Science of RK is responsible for general management of the process and preparing the legal framework of the UNT, the National Testing Center (NTC) MES RK prepares test materials and software, provides organizational and information work in the areas of the UNT (CP UNT), the state commission created by the order of RK establishes conditions and supervises the works for the UNT. Monitoring the conduct of UNT is authorized by the representatives of Ministry of Education and Science.

At processing the technology of UNT conduct there have been studied not only the technology of processing of test results offering countries, but experience of comprehensive testing implementation in the Republic of Kazakhstan in 1999-2003 as well. As a result, the technology has been chosen, which is original itself and does not mimic existing in the world.

The main technological feature of UNT in Kazakhstan is the principle of distributed processing of data and test results. This technology creating a database of test results and treatment were carried out in UNT CP, which are known to have been identified by MES RK. Examination materials are prepared and 
delivered to the NCSSET in UNT Before testing. The analysis of the results has been conducted at all points of Unified National Test, they were known on the same day. This technology, on the one hand, allows a reliable and open result processing, on the other hand, imposes additional conditions to ensure the safety and security information. Specially designed for UNT software met the requirements. For developing a database and result processing UNT CP were equipped with necessary technical equipment. For prompt transfer of the necessary information during UNT preparation and conduct telecommunication information system has been established connecting to all UNT CP and NTC. This national testing technology is applied only in Kazakhstan.

In 2004 UNT graduates passed the test of time for four subjects of school program, three of them (mother tongue, history of Kazakhstan, and mathematics) are required for all and a fourth subject was determined independently tested in accordance with the profile of the chosen specialty. Graduates in the UNT responded to 120 test items in three hours.

Such implementation form of UNT had been changed in subsequent years. In 2012 high school graduates passed UNT in five subjects (including Kazakh (Russian) for graduates of Russian (Kazakh) schools).

One important element of preparation for UNT was test compilation. Taking into account the experience of national comprehensive tests in 1999-2003 at UNT tests were applied to the choice of a correct answer.

For the development of tests for UNT:

- test specifications were defined;

- a group of test developers and experts from a number of qualified school teachers and university professors was created;

- validation and expertise of tests were carried out.

The combination of final and entrance exams obliged the simultaneous use of two types of tests: certification and competitive. In this certification tasks must meet a minimum level of state standards of high school education, in this regard, graduates answered correctly to the certification assignment, received a positive examination score. Usage of competitive challenges of three levels of difficulty allowedto assess graduates' educational achievements accurately and solve the problem of differentiating and ranking, which was necessary for the determination of holders of state educational grants. All these principles were reflected in the UNT specification tests.

Test developers were trained both theoretically and practically. Training was held by a leading expert from Russia in the field testing Ph.D., professor Avanessov V.S. In addition, the leading specialist teaching testing U.S. Service (ETS), Mark Zelman held workshops with NCSSET staff. Their good professional and practical training allowed to do the test of higher quality. Tests done by them were examined and valided, then the tests on the subjects were intended for use at UNT from the selected tasks.

Since the time Unified National Test has been a combination of final and entrance exams to universities and colleges, NCSSET together with the KAO NCSSET, UNT scoring scale (120 scores) in school assessment (5 points) was developed and approved by the MES RK.

UNT was conducted on the basis of special regional test points, district centers and some major cities. For UNT conduction there were opened 154 Test points (137 - in 2004, out of 85 - based on the schools in the district centers) that were provided with the necessary computer and telecommunications equipment. Depending on the number of applicants involved in tests the need to open the point in districts was determined. In case of a small amount of proposed test takers (250-500 people), ways for graduates of this school, along with graduates of other neighboring points to pass the tests were considered. In the context of the distance exceeded $200 \mathrm{~km}$, despite the small number of test takers in this region centers were opened. The points on this category were in the following areas: Karaganda, East Kazakhstan, Pavlodar, North Kazakhstan, Kostanay, Western Kazakhstan.

The main parameters determining test points were:

1. Transportation of graduates to the point at a distance not exceeding $200 \mathrm{~km}$;

2. 4 days" availability of classrooms for testing;

3. Availability of accommodation for graduates transported (hotel, a preventorium, a boarding school);

4. Availability of places for the food supply of transported students (dining room).

Each point of the UNT has the following computer and office equipment:

1. Computer Pentium-IV

2. An optical marker scanner

3. Laser Printer 
4. Copying machine.

Unified National Test was conducted in PP UNT according to the following stages:

1. Representatives of the Ministry of Education allocates the duty of audiences.

2. To pass the UNT school graduates go on audiences.

During start-up documents of each graduate are checked.

3. After seating the distribution of the examination materials for graduates was conducted. Each graduate was given: a book-questionnaire, a special form - answer sheet, which is designed for reading on the optical marker scanner, a copy of the answer sheet.

4. After clarification of the rules graduates were recorded the time - the beginning of the exam. The time allotted for testing was 180 minutes (3:00).

5. The order of the exam procedure was monitored by members of the State Commission and representatives of the MES RK.

6. Examination materials were transferred to all audiences by attendants on the act to the representatives of RK.

7. With the participation of representatives of MES RK, DNSC, Ministry of Education Programmer, members of the state commission test materials were processed, i.e. answer sheets were scanned, data were processed. Upon completion of examination materials processing, representatives of Ministry of Education and Science of RK receive the codes of correct answers on telecommunication network NCSSET.

8. After completion of above-listed works test results were posted to PP UNT.

Monitoring of the UNT was conducted by the authorized representatives of the RK - the leading specialists of the Ministry, universities, schools and education authorities. They had been trained and were directed to places a few days before the start of the UNT. Training of Representatives and Programmers of Ministry of Education and Science of RK for the UNT was performed as follows.

In just the time of the UNT in the years 2004-2012 1237861 of high school graduates participated, which is 79.96 percent of the total. UNT results changed towards improvement, the average UNT score in 2004 was 52.32 grades out of possible 120 grades, then in 2012 it reached 70.91 out of 125 . These results show that the quality of the UNT improved, for this purpose, various training courses, pilot testing, school's extracurricular classes are organized in the subjects tested. Results were analyzed by the UNT at different levels of education management and monitoring the resulting material is allowed to assess the state of the quality of students in institutions of secondary education in the context of each region, district, school. These materials became the basis for management decisions and guidance to improve the quality of education.

In general, the UNT is recognized by the public as an objective external quality control of school graduate knowledge. In 2012, the National Testing Center held sociological studies "Public attitude towards the Unified National Test," which results confirmed this statement. For example, according to the survey $70.8 \%$ of respondents support the conduct of the UNT and the benefits of the UNT called equal opportunity to enter the university, graduates from towns and villages ( $42.3 \%$ of respondents), improving the quality of training and knowledge of students $(30.6 \%)$.

Thus the conduct of the UNT allowed to provide equal conditions for taking final exams and entrance to all graduates of schools of our country.

It should also be pointed out that the introduction of the UNT was not only a decision of a purely educational problems of control, but the event was of great socio-political and social importance. Owing to the UNT introduction the conduct of an objective, public and transparent control of the level of high school graduates knowledge was made possible, moreover school teachers as well as the general public, including parents took an active part. Thus, the UNT was the first real step in the democratization of school management as well as provided an opportunity for parents and the general public and government representatives to participate in solving the problems of secondary education.

UNT has allowed the introduction of the following tasks:

- Obtain an objective assessment of the level of educational achievements of school graduates and educational services;

- A mechanism involving the public in schools to improve;

- Equal rights to all wishing to obtain a higher education are given;

- The infrastructure, ensuring quality of the UNT and processing of the results [5].

Conclusion

Quality in education is crucial to "nation-building" and individual empowerment. Kazakhstan had achieved the Millennium Development goal relating to education. In recent years Ministry of Education and Science (MES) has paid special attention to involvement and quality in education. As the country continues to enjoy accelerated economic growth, it has a great opportunity to invest substantially more in the education 
system, which would help it to ensure higher quality in education and avoid the exclusion of marginalized groups. In conclusion, I would like to say that the most important weapon for any country is an education quality.

Cite this article as: Alimkul A. (2019), Quality assessment system of secondary education in the Republic of Kazakhstan. Materials of International Practical Internet Conference “Challenges of Science". ISBN 978-601-323-144-0. Issue II, 2019. Page 92-97. https:// doi.org/10.31643/2019.018

\section{References}

[1] MES (Ministry for Education and Science of the Republic of Kazakhstan) (2010), "State Programme of Education Development for 2011-2020", Decree of the President of the Republic of Kazakhstan, No. 1118 from December 7, 2010, Astana.

[2] In identifying, briefly, these interdependent elements of an educational system we have also indicated what international evidence (Darling-Hammond, 2010; Hattie, 2012; Levin, 2008; Mourshed et al. 2010; Stobart, 2008) suggests are key levers for change, the most powerful perhaps being (high-stakes) assessment; teacher education and leadership at both the school level and in the wider administrative and support structure.

[3] LERK (Law on Education of the Republic of Kazakhstan) (2007), Government of the Republic of Kazakhstan, № 319-III from July 27, 2007 (with amendments and supplements as for 18.02.2014)

[4] Development of strategic directions for education reforms in Kazakhstan for 2015 - 2020 - Astana, 2014.

[5] Report 38th annual conference (2012), Balykbaev Tahir Ospanovich 